\title{
Molecular Absorbent Recirculating System for the Treatment of Acute Liver Failure in Surgical Patients
}

\author{
Daniel Inderbitzin, M.D., Beat Muggli, M.D., Annette Ringger, M.D., Guido Beldi, M.D., \\ Markus Gass, M.D., Beat Gloor, M.D., Dominik Ueblinger, M.D., Bruno Regli, M.D., \\ Jürg Reichen, M.D., Daniel Candinas, M.D.
}

\begin{abstract}
The Molecular Adsorbent Recirculating System (MARS) represents an attractive artificial liver support system for the treatment of liver insufficiency. However, neither indications for MARS treatment (i.e., after extended liver resection) nor criteria for discontinuation of therapy have been evaluated. Therefore, we analyzed the clinical data of all our surgical patients who received MARS treatment for acute liver failure $(n=7)$. The aim of the study was to identify prognostic indicators for survival. Four of 174 patients resected for hepatic malignancy at our institution received a total of 13 MARS treatments. Two additional patients were successfully bridged to orthotopic liver transplantation with seven MARS treatments and one patient was MARS supported after liver transplantation of a steatotic graft with three MARS treatments. Five of the seven patients survived and were dismissed an average of 31 days, ranging from 17 to 47 days, after the final MARS treatment. No technical complications or adverse effects were observed during the MARS treatments. Important prognostic factors for hepatic recovery and survival were indocyanin green plasma disappearance rates greater than $5 \% / \mathrm{min}$ and an increase in clotting factor $\mathrm{V}$ levels after each MARS treatment. We conclude that MARS therapy can be an effective treatment of postoperative liver insufficiency in the surgical hepatobiliary unit. (J GaSTROINTEST SURG 2005;9:11551162) (C) 2005 The Society for Surgery of the Alimentary Tract
\end{abstract}

KEY WORDS: Artificial liver support, liver surgery, acute liver failure, molecular adsorbent recirculating system, MARS, indocyanin green plasma disappearance rate

Intense liver regeneration follows hepatic resections that are required for removal of primary or secondary liver tumors in humans. Excellent hepatic regeneration and an uncomplicated recovery can be expected with a $50 \%$ or greater remnant of total liver mass that corresponds to at least $1.2 \%$ of body weight (BW). ${ }^{1-3}$ More extensive hepatectomies, such as resections of $50-70 \%$ of total liver mass, that leave smaller liver remnants can result in impaired regeneration. The minimum liver remnant needed for survival in patients is currently considered to be $0.8 \%$ of BW. ${ }^{1,4-6}$

Synthetic activity and detoxification capacity of the regenerating liver may fail, typically on the third to fourth day after surgery, when extended hepatic resections result in critically low remnant liver mass. ${ }^{6}$ In these clinical circumstances the Molecular Adsorbent Recirculating System (MARS; Gambro Rostock AG, Rostock, Germany) represents an attractive artificial liver support system for the treatment of the acute liver insufficiency. ${ }^{7-10}$ MARS uses a hollow-fiber dialysis module containing an albumin-impregnated polysulfone membrane that separates the patient's blood and the $20 \%$ albumin dialysate in the extracapillary compartment. The albumin dialysate is cleansed from water-soluble toxins by passage through a hemodialysis module, and albumin-bound toxins are removed by perfusion over activated charcoal and resin. ${ }^{11}$

Reports on the use of MARS for the treatment of hepatic failure after major liver resection are scarce and only 12 patients from five different groups have

Presented at the Forty-Sixth Annual Meeting of The Society for Surgery of the Alimentary Tract, Chicago, Illinois, May 14-18, 2005 (oral presentation).

From the Departments of Visceral and Transplant Surgery (D.I., B.M., A.R., G.B., M.G., B.G., D.C.), Intensive Care Medicine (B.R.), and Nephrology (D.U.), University Hospital Bern, and the Institute of Clinical Pharmacology (J.R.), University of Bern, Bern, Switzerland.

Reprint requests: Daniel Inderbitzin, M.D., Department of Visceral and Transplant Surgery, University Hospital Bern, CH-3010 Bern, Switzer-

land. e-mail: daniel.inderbitzin@insel.ch 
so far been described. ${ }^{9,12-15}$ The reported patient mortality rate was $75 \%$ (9/12). Similarly, reports on the outcome of MARS therapy in the liver transplant setting, such as bridging to orthotopic liver transplantation (OLT), treatment of primary nonfunction after OLT, or therapy of delayed graft function after OLT, are limited to single reports. ${ }^{9,11,16-21}$

Neither clear indications for the postoperative initiation of MARS treatment, such as after major hepatic resections, nor criteria for discontinuation of therapy have been evaluated. Therefore, we prospectively analyzed clinical data from all of our surgical patients who received MARS treatment. The aim of the study was to identify prognostic parameters for survival during MARS therapy.

\section{MATERIAL AND METHODS}

The clinical data obtained from the surgical patients $(\mathrm{n}=7)$ who were included in the study are summarized in Table 1 . Informed consent for MARS treatment was obtained from the patients or an immediate family member (institutional approval: 1.05.01.30.-17). Indications for the initiation of

Table 1. Patient Characteristics, Diagnosis, Surgical Treatment, and Outcome After MARS Treatment

\begin{tabular}{|c|c|c|c|c|c|c|}
\hline $\begin{array}{l}\text { Patient } \\
\text { (Gender, } \\
\text { Age [yr]) }\end{array}$ & Group & Diagnosis & $\begin{array}{c}\text { Surgical } \\
\text { Intervention } \\
\text { (Resected } \\
\text { Couinaud } \\
\text { Liver } \\
\text { Segments) }\end{array}$ & $\begin{array}{l}\text { Indication for } \\
\text { Initiation } \\
\text { of MARS } \\
\text { Treatment }\end{array}$ & $\begin{array}{c}\text { MARS } \\
\text { Cycles (n) }\end{array}$ & $\begin{array}{l}\text { MARS-Responder? } \\
\text { Comment on } \\
\text { Clinical Course }\end{array}$ \\
\hline $1(\mathrm{~F}, 30)$ & Group A & Cholangiocarcinoma & $\begin{array}{l}\text { Extended left } \\
\text { hepatectomy } \\
\text { (I, II, III, IV, } \\
\text { V, VIII) } \\
\text { Hepatic vein } \\
\text { reconstruction }\end{array}$ & $\begin{array}{l}\text { Factor } \\
\qquad \mathrm{V}<30 \%\end{array}$ & 3 & $\begin{array}{l}\text { Yes; discharged } \\
17 \text { days after MARS }\end{array}$ \\
\hline $2(M, 65)$ & Group A & Cholangiocarcinoma & $\begin{array}{l}\text { Extended left } \\
\text { hepatectomy } \\
\text { (II, III, IV, } \\
\text { part. V, } \\
\text { part. VIII) } \\
\text { Hepatic artery } \\
\text { reconstruction }\end{array}$ & $\begin{array}{l}\text { Factor } \\
\qquad \mathrm{V}<30 \%\end{array}$ & 3 & $\begin{array}{l}\text { Yes; discharged } \\
31 \text { days after MARS }\end{array}$ \\
\hline $3(M, 48)$ & Group B & $\begin{array}{l}\text { Gallbladder } \\
\text { carcinoma }\end{array}$ & $\begin{array}{l}\text { Extended left } \\
\text { hepatectomy } \\
\text { (I, II, III, } \\
\text { IV, V, part. VIII) }\end{array}$ & Asterixis & 2 & $\begin{array}{l}\text { No; died } 1 \text { day after } \\
\text { discontinuation } \\
\text { of MARS }\end{array}$ \\
\hline $4(M, 64)$ & Group B & $\begin{array}{l}\text { Hepatocellular } \\
\text { carcinoma in } \\
\text { cirrhosis } \\
\text { (hemochromatosis) }\end{array}$ & $\begin{array}{c}\text { Extended right } \\
\text { hepatectomy } \\
\text { (part. IV, V, } \\
\text { VI, VII, VIII) }\end{array}$ & Asterixis & 5 & $\begin{array}{l}\text { No; died } 2 \text { days after } \\
\text { discontinuation } \\
\text { of MARS }\end{array}$ \\
\hline $5(\mathrm{~F}, 66)$ & Group B & $\begin{array}{l}\text { Late-onset hepatic } \\
\text { failure in } \\
\text { autoimmune } \\
\text { hepatitis }\end{array}$ & OLT & Asterixis & 6 & $\begin{array}{l}\text { No; bridge to OLT. } \\
\text { discharged } 45 \\
\text { days after OLT }\end{array}$ \\
\hline $6(M, 34)$ & Group B & $\begin{array}{l}\text { Primary } \\
\text { non-function } \\
\text { after OLT }\end{array}$ & Re-OLT & $\begin{array}{l}\text { Factor } \\
\qquad \mathrm{V}<30 \%\end{array}$ & 1 & $\begin{array}{l}\text { No; bridge to } \\
\text { re-OLT. } \\
\text { discharged } 17 \\
\text { days after re-OLT }\end{array}$ \\
\hline $7(\mathrm{~F}, 65)$ & Group A & $\begin{array}{l}\text { Delayed graft } \\
\text { function } \\
\text { after OLT } \\
\text { (steatotic graft) }\end{array}$ & OLT & Asterixis & 3 & $\begin{array}{l}\text { Yes; discharged } \\
\quad 47 \text { days after MARS }\end{array}$ \\
\hline
\end{tabular}

OLT $=$ orthotopic liver transplantation; Part. = partially resected liver segment.

Group A includes all MARS responding and surviving patients. Group B contains all MARS nonresponding patients (nonsurvivors and patients successfully bridged to orthotopic liver transplantation). 
MARS therapy were liver insufficiency with hepatic encephalopathy and asterixis in four of the patients and clotting factor $\mathrm{V}$ levels below $30 \%$ in three intubated patients.

\section{MARS Therapy}

A central venous access was established by introducing a Mahurkar dual-lumen catheter (Tyco Healthcare Switzerland Ltd., Wollerau, Switzerland). Patients were then connected to the primed MARS monitor (Gambro Rostock AG) that was operated in conjunction with a Fresenius 4000S (Bad Homburg, Germany) dialysis machine. A standard dialysate containing dextrose was used at a rate of $500 \mathrm{ml} / \mathrm{min}$ with sodium concentrations slightly above $140 \mathrm{mmol} / \mathrm{L}$ and a bicarbonate concentration of $35 \mathrm{mmol} / \mathrm{L}$. Patient blood and albumin flow rates within the MARS monitor were adjusted between 150 and $250 \mathrm{ml} / \mathrm{min}$. Heparin was administered to maintain activated clotting time (ACT) between 100 and 180 seconds. MARS treatment was limited to a maximum of 8 hours, followed by a 16-hour MARS-free interval.

\section{Laboratory Parameters}

Liver function tests including coagulation parameters, complete blood cell count, serum electrolytes, ammonia, and creatinine were determined before and after each MARS treatment. Indocyanin green (ICG) plasma disappearance rates (ICG-PDR) were measured after injection of $0.5 \mathrm{mg}$ ICG $/ \mathrm{kg}$ body weight (ICG-Pulsion; Pulsion Medical Systems, Munich, Germany) by the use of the noninvasive LIMON monitor (Pulsion Medical Systems).

\section{Patient Groups}

Two patient groups, based on the hepatic response under MARS therapy, were compared to identify potential prognostic factors during MARS therapy (Table 1). The two groups were MARS responders (group A, surviving patients after extended liver resections and with delayed function of a steatotic liver graft; $\mathrm{n}=3 ; 9$ MARS cycles) and MARS nonresponders (group $\mathrm{B}$, nonsurvivors and patients bridged to OLT; $\mathrm{n}=4 ; 14$ MARS cycles).

\section{Statistical Analysis}

Results are expressed as mean \pm SD. Data were statistically analyzed using the Jandel Scientific Software (1.0; Jandel Scientific, San Raffael, CA). $t$-Tests were used to compare normally distributed data between groups, and paired $t$-test analysis was performed to compare laboratory parameters before and after MARS treatment. For nonnormally distributed data, a Mann-Whitney rank sum test was applied to compare groups and the Wilcoxon signed rank test was used for paired analysis. The significance level was set at $P<0.05$.

\section{RESULTS}

During the study period, 212 hepatic resections were performed in 174 patients at our institution. Only 4 patients of the 20 with extended liver resections required MARS support. Three $(5.4 \%)$ of a total of 56 OLT patients received pretransplant or posttransplant MARS therapy.

Two patients from group A $(n=3)$, after undergoing extended hepatic resection, were treated daily for 3 days beginning on postoperative day 2. One patient with a delayed graft function after OLT received three MARS cycles 3 days post-OLT on. These three patients were discharged from the hospital 17, 31, and 47 days after MARS.

One patient from group B $(n=4)$, after a right portal branch occlusion and a consecutive extended right hepatectomy due to hepatocellular carcinoma (HCC) in a cirrhotic liver (hemochromatosis), was treated from day 7 to day 11 . MARS was then discontinued because of a lack of clinical improvement. The patient died 2 days later. An extended left hepatectomy and right portal vein reconstruction were performed in one patient with gallbladder carcinoma. MARS treatment was initiated on postoperative day 2 and discontinued after two cycles to comply with the patient's request upon receiving histopathologic confirmation of a hepatic tumor remnant. The patient died 1 day later. Two patients in this group were successfully bridged to OLT and re-OLT and discharged 17 and 45 days after MARS treatment.

Ten of 23 MARS therapies lasted the full 8 hours. The other 13 MARS treatments were discontinued early $(6.3 \pm 1.5$ hours $)$ due to a filter obstruction. No differences in therapy time were observed between groups A and B. An average blood flow of $188 \pm 19 \mathrm{ml} / \mathrm{min}$ and corresponding albumin flow in the MARS monitor of $237 \pm 19 \mathrm{ml} / \mathrm{min}$ were used in both groups ( $P=$ NS between groups). No adverse effects were encountered during the 166 hours of MARS therapy.

The average heparin dose administered during MARS cycles was $530 \pm 375 \mathrm{IE} / \mathrm{hr}$ in group A and, significantly lower, $120 \pm 160 \mathrm{IE} / \mathrm{hr}(P<0.05)$, in group $B$. A trend toward higher heparin doses with every additional MARS cycle was detected in group A. Most important, except for two minor bleeding incidents at the catheter insertion site, no severe bleeding complications were observed. 


\section{Model for End-Stage Liver Disease (MELD) Score}

Initial MELD scores ${ }^{22}$ added up to 19, 19, and 31 in group $A$ and 15, 22, 40, and 40 in group B. MELD scores significantly $(P<0.001)$ decreased $(-3.9 \pm$ 2.2) in group A after MARS treatment; they were unchanged $(P=\mathrm{NS})$ in group $\mathrm{B}(-0.9 \pm 2.8)$.

\section{Laboratory Parameters}

Hemoglobin values and leukocyte counts did not differ between the groups, nor did MARS therapy alter these values. Initial platelet counts were similar in both groups (Table 2). A paired analysis revealed significant platelet loss during MARS treatment in group B $(P<0.05)$. Water-soluble creatinine and ammonia were efficiently $(P<0.05)$ removed by MARS therapy. Bilirubin and alkaline phosphatase levels were significantly higher $(P<0.05)$ in group $\mathrm{B}$ patients. Bilirubin levels only decreased in group $\mathrm{B}(P<0.05)$ during the MARS therapy.

\section{Coagulation Parameters}

One patient in group A and two patients in group $B$ received fresh frozen plasma (FFP) before MARS therapy. Clotting parameters obtained within 24 hours after FFP administration were excluded from analysis.
International normalized ratio (INR) values were significantly lower $(P<0.05)$ in group A both before and after MARS treatment (Table 2). In a paired analysis, INR values increased during MARS therapy $(P<0.05)$ in group B while they were unaltered in group A $(P=\mathrm{NS})$. All group A patients had INR values below 2.0 at all time points. It should be noted that only patients of group B received FFP during MARS therapy.

Initial clotting factor $\mathrm{V}$ levels were $24.7 \pm 7.5 \%$ in group A and $21.8 \pm 21.5 \%$ in group B. Factor $\mathrm{V}$ levels increased significantly $(P<0.05)$ between MARS cycles in group A by $12.2 \pm 8.0 \%$ and the average factor $\mathrm{V}$ levels decreased by $0.4 \pm 6.1 \%$ in group B $(P=\mathrm{NS})$ (Fig. 1). All patients who had clotting factor $V$ levels spontaneously reach greater than $40 \%$ during MARS therapy recovered.

\section{Noninvasive Measurement of ICG-PDR}

ICG-PDRs were obtained before and after MARS treatment. Values remained stable throughout MARS cycles $(P=\mathrm{NS})$. Average ICG-PDRs for group A patients were $7.0 \pm 1.1 \% / \mathrm{min}$. Corresponding values for group B were significantly lower (2.5 $\pm 1.1 \% / \mathrm{min}, P<0.0001$ ) (Fig. 2). No patient with an ICG-PDR below $5.0 \% / \mathrm{min}$ survived without OLT.

Table 2. Laboratory Parameters of Surgical Patients With Liver Failure Before and After MARS Therapy

\begin{tabular}{|c|c|c|c|}
\hline Laboratory Parameters & & $\begin{array}{l}\text { Group A }(\mathrm{n}=3) \\
(9 \text { MARS Cycles) }\end{array}$ & $\begin{array}{c}\text { Group B }(n=4) \\
(14 \text { MARS Cycles) }\end{array}$ \\
\hline \multirow[t]{2}{*}{ Thrombocytes $\left(10^{9} / \mathrm{L}\right)$} & Pre-MARS & $101.4 \pm 51.0$ & $87.5 \pm 61.4$ \\
\hline & Post-MARS & $95.6 \pm 43.2$ & $64.2 \pm 47.6^{*}$ \\
\hline \multirow{2}{*}{ Creatinine $(\mu \mathrm{mol} / \mathrm{L})$} & Pre-MARS & $143.3 \pm 57.7$ & $181.8 \pm 139.5$ \\
\hline & Post-MARS & $100.3 \pm 30.5^{*}$ & $141.5 \pm 115.0^{*}$ \\
\hline \multirow[t]{2}{*}{ Ammonia $(\mu \mathrm{mol} / \mathrm{L})$} & Pre-MARS & $37.9 \pm 31.4$ & $45.2 \pm 37.7$ \\
\hline & Post-MARS & $26.2 \pm 18.6^{*}$ & $35.9 \pm 28.9^{*}$ \\
\hline \multirow[t]{2}{*}{ Aspartate aminotransferase (U/L) } & Pre-MARS & $2151 \pm 2178$ & $1408 \pm 1633$ \\
\hline & Post-MARS & $1254 \pm 1077$ & $1007 \pm 1024$ \\
\hline \multirow[t]{2}{*}{ Alanine aminotransferase (U/L) } & Pre-MARS & $2534 \pm 2713$ & $1080 \pm 1083$ \\
\hline & Post-MARS & $1804 \pm 1859$ & $932 \pm 1020$ \\
\hline \multirow[t]{2}{*}{ Alkaline phosphatase (U/L) } & Pre-MARS & $75 \pm 31$ & $258 \pm 113^{\dagger}$ \\
\hline & Post-MARS & $76 \pm 29$ & $227 \pm 95^{\dagger}$ \\
\hline \multirow[t]{2}{*}{ Bilirubin $(\mu \mathrm{mol} / \mathrm{L})$} & Pre-MARS & $115.1 \pm 76.0$ & $264.8 \pm 176.7^{\dagger}$ \\
\hline & Post-MARS & $96.4 \pm 60.3$ & $216.4 \pm 119.0^{*} \dagger$ \\
\hline \multirow{2}{*}{ Prothrombin time (INR) } & Pre-MARS & $1.44 \pm 0.26$ & $2.22 \pm 0.45^{\dagger}$ \\
\hline & Post-MARS & $1.41 \pm 0.26$ & $2.66 \pm 0.78^{*} \dagger$ \\
\hline
\end{tabular}

Average serum laboratory parameters (mean \pm SD) of MARS responding patients (group A) and MARS nonresponding patients (group B) before (Pre-) and after (Post-) MARS therapy are presented. A significant decrease $\left({ }^{*} P<.05\right)$ of thrombocyte counts was seen in group B after MARS therapy. This indicated platelet loss during treatment. Creatinine and ammonia levels in the blood decreased after MARS in both groups as expected. Significant differences $\left({ }^{\dagger} P<.05\right)$ between groups A and B were detected in alkaline phosphatase, bilirubin, and INR values. In a paired anlaysis comparing values before and after MARS treatment, a significant decrease in bilirubin values $\left({ }^{*} P<.05\right)$ and a rise of INR $\left({ }^{\star} P<.05\right)$ values was seen in group B only. 


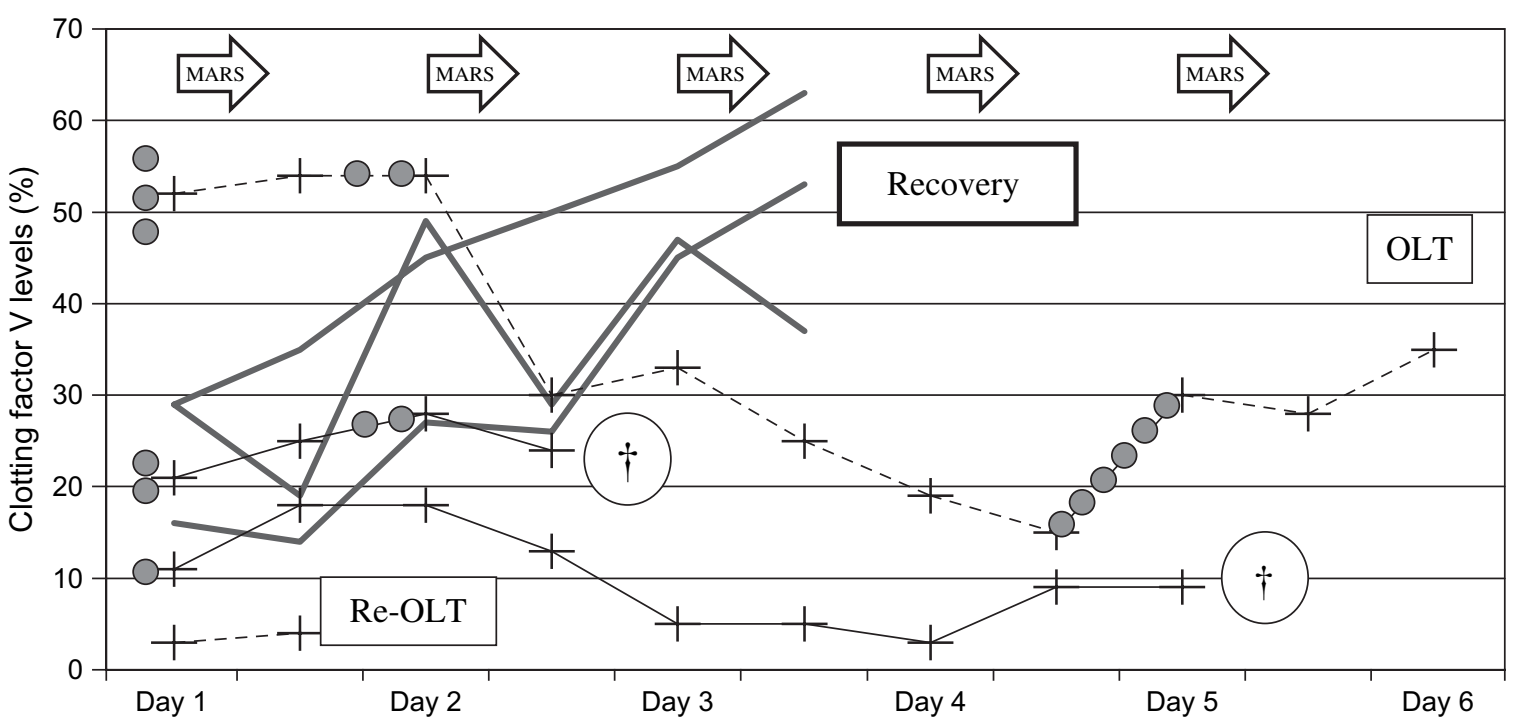

Fig. 1. Clotting factor $V$ levels in patients with liver failure during MARS therapy. Depicted are clotting factor $V$ levels of all patients during the entire period of MARS therapy (MARS, arrow). Three patients received fresh frozen plasma (FFP) (O) before the initiation of MARS therapy. Only group B patients received FFP during MARS treatment. After superurgent listing for OLT, one patient received six FFP treatments on day 5 . Initial factor $\mathrm{V}$ levels were $<30 \%$ in six of seven patients. Surviving patients (bold line; Recovery) showed an increase of factor $\mathrm{V}$ levels with each additional MARS cycle (a MARS cycle includes 8 hours of MARS treatment followed by 16 hours MARS free). Two patients died (fine line; $\dagger$ ) after discontinuation of MARS treatment. Two patients (dotted line) were successfully bridged to OLT and re-OLT.

\section{DISCUSSION}

MARS therapy has proved to be safe for the treatment of liver failure in over 3000 patients. ${ }^{9}$ However, the reported mortality for MARS-treated surgical patients with hepatic failure after major liver resection has been reported at 75\%.9,13-15 Patient selection for liver surgery and the indications for MARS treatment clearly influence the survival data. Complete tumor resection resulted in a small-for-size liver remnant $(<0.8 \% \mathrm{BW})$ in three of four resected patients in this series. The remaining resected patient had hemochromatosis-related liver cirrhosis in the left liver remnant. To date, no appropriate indicators have been validated to a priori determine survival of patients with severe posthepatectomy liver dysfunction. We therefore initiated MARS therapy in surgical patients early on, when it was apparent that liver insufficiency was imminent. MARS treatment was initiated as soon as asterixis was present or, in the case of prolonged mechanical ventilation and complete muscle relaxation, when clotting factor $\mathrm{V}$ levels were below $30 \%$. Similarly, we suggest the early use of MARS $^{9,11,16,17}$ as a bridge to OLT, for the treatment of primary nonfunction after OLT, and as a temporary support strategy after transplantation of a steatotic liver graft.
Several prognostic parameters correlated well with survival in this analysis. ICG-PDR values have been used for the past 20 years to monitor hepatic function after injury, ${ }^{23}$ to assess liver function before and during major hepatic resections, ${ }^{24}$ and to determine suitability as well as early graft dysfunction in the liver transplant setting. ${ }^{25,26}$ In our study, ICGPDRs remained low, less than $10 \% / \mathrm{min}$, despite significant clinical and synthetic improvement in the group A patients during the first days of liver supportive therapy. Noninvasive ICG-PDR monitoring seems inappropriate for the verification of successful hepatic regeneration early but was clearly able to indicate patients survival if an ICG-PDR greater than $5 \% / \mathrm{min}$ was determined (Fig. 2). The values observed are considerably lower than those described in critically ill patients with hepatic dysfunction. ${ }^{27,28}$ The role for ICG-PDR in evaluating surgical patients requires further prospective investigation.

Interestingly, INR and bilirubin values also correlated well with survival. They may contain a predictive value not only in the setting of chronic (MELD score $)^{22}$ but also in acute postoperative liver failure. Interestingly, the described ${ }^{7}$ significant decrease in serum bilirubin levels during MARS therapy was observed only in group B. 


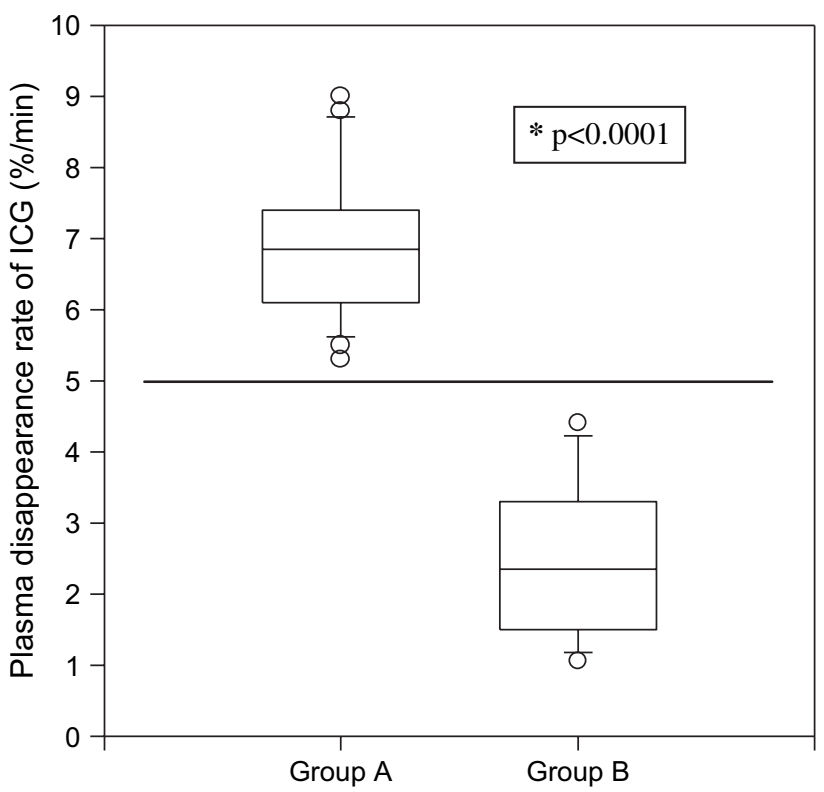

Fig. 2. Indocyanin green plasma disappearance rates (ICGPDRs) in surgical patients with liver insufficiency. Tukey box plot: Depicted are ICG-PDR before (Pre) and after (Post) MARS treatment of MARS responding patients (group A) and MARS nonresponding patients (group B). The box boundaries indicate the 25 th and 75 th percentiles. The line inside the box shows the value of the 50th percentile. Capped bars indicate the 10th and 90th percentiles, and symbols mark outliers. Patients responding to MARS treatment (group A) had significantly higher ICG-PDR than nonresponders (group B). An ICG-PDR of $>5.0 \% / \mathrm{min}$ appears to separate survivors from nonsurvivors $\left({ }^{*} P<0.0001\right)$.

Clotting factor $\mathrm{V}$ levels can predict the outcome in acute liver failure and coagulopathy. ${ }^{29}$ For this reason we systematically assessed factor $\mathrm{V}$ levels before and after each MARS treatment. Factor $V$ levels acted as a surrogate marker for synthetic hepatic activity, and we noted a significant increase between each MARS cycle in patients of group A that indicated an early improvement in liver function (Fig. 1).

The alterations in systemic heparin response and variations in heparin clearance rates in acute liver disease are well recognized. ${ }^{30}$ Additionally, heparin elimination shows considerable interindividual variations. ${ }^{31}$ A recent systematic review of artificial and bioartificial liver support systems from the Cochrane Hepato-Biliary group identified bleeding complications as the most important and serious adverse events during treatment of hepatic failure. ${ }^{32}$ Therefore, we closely monitored ACT values during MARS therapy. In contrast to other reports, ${ }^{10,15}$ no bleeding problems were observed in our series. We strongly recommend tight control of ACT values and cautious administration of heparin. Thirteen MARS Flux Dialyzers were lost during the treatment of five different patients as a consequence of this policy. Clotting of the MARS system is a nonreversible event in our experience. Neither rinsing of the system nor additional administration of a heparin bolus can rescue the filter. In cases of filter obstruction, and when elevated transmembrane pressure indicates imminent hemolysis, we reduce the blood and albumin perfusion rate and terminate the MARS treatment.

Our initial experience with MARS treatment of surgical patients with liver failure shows promising results with five of seven patients surviving. The beneficial effect of MARS therapy on our surgical patients is difficult to determine, and the potential prognostic factors identified in our series as well as the MARS system itself require further validation in additional prospective randomized controlled trials.

\section{CONCLUSION}

MARS therapy is safe and can be an effective treatment for postoperative liver insufficiency. An important prognostic factor for survival identified in our patients was an ICG-PDR of greater than $5 \% / \mathrm{min}$. MARS therapy represents an important therapeutic option for the treatment of severe hepatic dysfunction in the surgical hepatobiliary unit.

\section{REFERENCES}

1. Shoup M, Gonen M, D'Angelica M, et al. Volumetric analysis predicts hepatic dysfunction in patients undergoing major liver resection. J GASTROINTEST SURG 2003;7:325-330.

2. Urata K, Hashikura Y, Ikegami T, Terada M, Kawasaki S. Standard liver volume in adults. Transplant Proc 2000;32: 2093-2094.

3. Heinemann A, Wischhusen F, Puschel K, Rogiers X. Standard liver volume in the Caucasian population. Liver Transpl Surg 1999;5:366-368.

4. Kiuchi T, Tanaka K. How much liver does the patient need? In: Rogiers X, Bismuth H, Busuttil RW, Broering DC, Azoulay D, eds. Split Liver Transplantation. Darmstadt: Springer, 2002, pp 105-114.

5. Schindl MJ, Redhead DN, Fearon KC, Garden OJ, Wigmore SJ. The value of residual liver volume as a predictor of hepatic dysfunction and infection after major liver resection. Gut 2005;54:289-296.

6. Yigitler C, Farges O, Kianmanesh R, Regimbeau JM, Abdalla EK, Belghiti J. The small remnant liver after major liver resection: how common and how relevant? Liver Transpl 2003;9:S18-S25.

7. Stange J, Mitzner SR, Risler T, et al. Molecular Adsorbent Recycling System (MARS): clinical results of a new membrane-based blood purification system for bioartificial liver support. Artif Organs 1999;23:319-330.

8. Mitzner SR, Stange J, Klammt S, Peszynski P, Schmidt R, Noldge-Schomburg G. Extracorporeal detoxification using the Molecular Adsorbent Recirculating System for critically 
ill patients with liver failure. J Am Soc Nephrol 2001; 12(suppl 17):S75-S82.

9. Sen S, Williams R, Jalan R. Emerging indications for albumin dialysis. Am J Gastroenterol 2005;100:468-475.

10. Heemann U, Treichel U, Loock J, et al. Albumin dialysis in cirrhosis with superimposed acute liver injury: a prospective, controlled study. Hepatology 2002;36:949-958.

11. Stange J, Hassanein TI, Mehta R, Mitzner SR, Bartlett RH. The molecular adsorbents recycling system as a liver support system based on albumin dialysis: a summary of preclinical investigations, prospective, randomized, controlled clinical trial, and clinical experience from 19 centers. Artif Organs 2002;26:103-110.

12. van de Kerkhove MP, de Jong KP, Rijken AM, de Pont AC, van Gulik TM. MARS treatment in posthepatectomy liver failure. Liver Int 2003;23(suppl 3):44-51.

13. Kellersmann R, Gassel HJ, Buhler C, Thiede A, Timmermann W. Application of Molecular Adsorbent Recirculating System in patients with severe liver failure after hepatic resection or transplantation: initial single-centre experiences. Liver 2002;22(suppl 2):56-58.

14. Lamesch P, Jost U, Schreiter D, et al. Molecular Adsorbent Recirculating System in patients with liver failure. Transplant Proc 2001;33:3480-3482.

15. Mullhaupt B, Kullak-Ublick GA, Ambuhl P, Maggiorini M, Stocker R, Kadry Z, Clavien PA, Renner EL. First clinical experience with Molecular Adsorbent Recirculating System (MARS) in six patients with severe acute on chronic liver failure. Liver 2002;22(suppl 2):59-62.

16. Novelli G, Rossi M, Pretagostini R, et al. MARS (Molecular Adsorbent Recirculating System): experience in 34 cases of acute liver failure. Liver 2002;22(suppl 2):43-47.

17. Wilmer A, Nevens F, Evenepoel P, Hermans G, Fevery J. The Molecular Adsorbent Recirculating System in patients with severe liver failure: clinical results at the K.U. Leuven. Liver 2002;22(suppl 2):52-55.

18. Awad SS, Swaniker F, Magee J, Punch J, Bartlett RH. Results of a phase I trial evaluating a liver support device utilizing albumin dialysis. Surgery 2001;130:354-362.

19. Contreras J, Poniachik J, Oksenberg D, et al. [Albumin dialysis MARS (Molecular Adsorbent Recirculating System) as a bridge for liver transplantation in acute liver failure. Report of three cases]. Rev Med Chil 2004;132:601-607.
20. Ding Y'T, Xu QX, Qiu YD, Yang YJ. Molecular adsorbent recycling system in treating patients with acute liver failure: a bridge to liver transplantation. Hepatobiliary Pancreat Dis Int 2004;3:508-510.

21. Lahdenpera A, Koivusalo AM, Vakkuri A, Hockerstedt K, Isoniemi H. Value of albumin dialysis therapy in severe liver insufficiency. Transpl Int 2005;17:717-723.

22. UNOS. MELD calculator. Available at http://www.unos.org/ resources/meldpeldcalculator. .asp?index $=98$.

23. Gottlieb ME, Stratton HH, Newell JC, Shah DM. Indocyanine green. Its use as an early indicator of hepatic dysfunction following injury in man. Arch Surg 1984;119: 264-268.

24. Niemann CU, Roberts JP, Ascher NL, Yost CS. Intraoperative hemodynamics and liver function in adult-to-adult living liver donors. Liver Transpl 2002;8:1126-1132.

25. Jalan R, Plevris JN, Jalan AR, Finlayson ND, Hayes PC. A pilot study of indocyanine green clearance as an early predictor of graft function. Transplantation 1994;58:196-200.

26. Hsieh CB, Chen CJ, Chen TW, et al. Accuracy of indocyanine green pulse spectrophotometry clearance test for liver function prediction in transplanted patients. World J Gastroenterol 2004;10:2394-2396.

27. Kimura S, Yoshioka T, Shibuya M, Sakano T, Tanaka R, Matsuyama $S$. Indocyanine green elimination rate detects hepatocellular dysfunction early in septic shock and correlates with survival. Crit Care Med 2001;29:1159-1163.

28. Sakka SG, Meier-Hellmann A. Indocyanine green for the assessment of liver function in critically ill patients. Berlin, Heidelberg, New York: Springer, 2001, pp 18-26.

29. Elinav E, Ben-Dov I, Hai-Am E, Ackerman Z, Ofran Y. The predictive value of admission and follow up factor $\mathrm{V}$ and $\mathrm{VII}$ levels in patients with acute hepatitis and coagulopathy. J Hepatol 2005;42:82-86.

30. Sette H, Hughes RD, Langley PG, Gimson AE, Williams R. Heparin response and clearance in acute and chronic liver disease. Thromb Haemost 1985;54:591-594.

31. de Swart CA, Nijmeyer B, Roelofs JM, Sixma JJ. Kinetics of intravenously administered heparin in normal humans. Blood 1982;60:1251-1258.

32. Kjaergard LL, Liu J, Als-Nielsen B, Gluud C. Artificial and bioartificial support systems for acute and acute-on- chronic liver failure: a systematic review. JAMA 2003;289:217-222.

\section{Discussion}

Dr. Fan Stange (Rostock, Germany): The albumin dialysis system using MARS was developed as a detoxification support system to support patients in liver failure by removing toxins from blood to improve hepatic encephalopathy and lessen the hyperdynamic circulation that leads to hypertension and kidney failure. These items are factors that alter survival. The majority of data have been collected in patients with chronic liver disease who have acute liver failure. Data of postsurgical complications that end in liver failure are rather rare, and here is what I personally think is the specific value of your presentation. In addition to postsurgical liver failure, other covariants might affect outcome. Knowing about those covariants would help us to assign the therapy to those patients who would have the biggest benefit from it.

From your presentation, the cofactors that were predictive for a good outcome can be divided into two major groups, the first group having high INR, high bilirubin, and a low indocyanine green clearance. The second group had the ability to show improvement in liver function in the phases between treatments. So in the group of patients who when off treatment have recovery of liver function, I have three questions.

First, with the exception of clotting factors or INR, your parameters, bilirubin and indocyanine 
green clearance, can be signs of either poor hepatocellular function or postsurgical biliary complication. What is your personal opinion about postsurgical biliary complications in predicting outcome?

The second question - we found that a very important cofactor in dealing with liver failure is, in the presence of infection developing into sepsis, the successful treatment of the sepsis with antibiotics was important. Can you make any short comment on that?

And the third question is, usually postsurgical liver failure patients have low blood pressure and problems with hemodynamics. Usually this requires the use of continuous kidney support. For liver support, we don't know whether continuous or intermittent might be preferable. Was your specific intention to use intermittent treatments?

Dr. Inderbitzin: The answer to the first question - we treated all patients between day 2 and 3 after resection. So they were still in the phase of small liver remnant size. So these patients do have a problem with their hepatocellular mass.

Question number 2 about sepsis - we are trying to start treatment early and it is too early for septic complications. Septic complications are a contraindication in our clinic to start the MARS treatment because we are not sure about what we remove and we might even harm the septic patient with a MARS treatment. That might change in the future.

The third question was about hemodynamics. All patients were hemodynamically stable and they did not change during MARS treatment. The specific reason we chose 8 hours and intermittent treatment is that our team cannot handle the 24 hours that are also suggested by your group. That might be the future, but for the beginning, an intermittent treatment was more practical.

Dr. Steven Curley (Houston, TX): I have two questions for you. To follow up a little bit on the question that was asked previously, you presented seven patients. That is seven patients out of how many total who had an extended resection during the time you have been doing this?

Number 2, do you routinely calculate the future liver remnant on your patients to know if you are going to have a patient who may be at risk for liver insufficiency, and should those patients have portal vein embolization prior to their resection?

Dr. Inderbitzin: In the same period of time we performed 212 liver resections, including 24 extended resections that were comparable to the ones that required MARS therapy. There were four patients after resection and three patients were periOLT. I used the peri-OLTs as baseline of no liver function.

Unfortunately, we did not receive the liver volume from our radiologist that would allow us to determine the presence of a small liver remnant before resection. We do use the portal vein embolization. We used it in one of the described patients to induce liver regeneration. 